\title{
Increasing the success rate of interfacial polymerization on hollow fibers by the single-step addition of an intermediate layer
}

\author{
M. Mohammadifakhr ${ }^{\mathrm{a}}$, K. Trzaskus ${ }^{\mathrm{b}}$, A.J.B. Kemperman ${ }^{\mathrm{a}}$, H.D.W. Roesink ${ }^{\mathrm{a}}$, J. de Grooth ${ }^{\mathrm{a}, \mathrm{c}, *}$ \\ ${ }^{\mathrm{a}}$ Membrane Science and Technology Cluster, Department of Science and Technology, Mesa + Institute for Nanotechnology, University of Twente, P.O. Box 217, 7500 AE \\ Enschede, the Netherlands \\ ${ }^{\mathrm{b}}$ Department of Research and Development, Aquaporin A/S, Nymøllevej 78, 2800 Kongens Lyngby, Denmark \\ ${ }^{\mathrm{c}}$ Films in Fluids, Faculty of Science and Technology, Mesa + Institute for Nanotechnology, University of Twente, P.O. Box 217, 7500 AE Enschede, the Netherlands
}

G R A P H I C A L A B S T R A C T
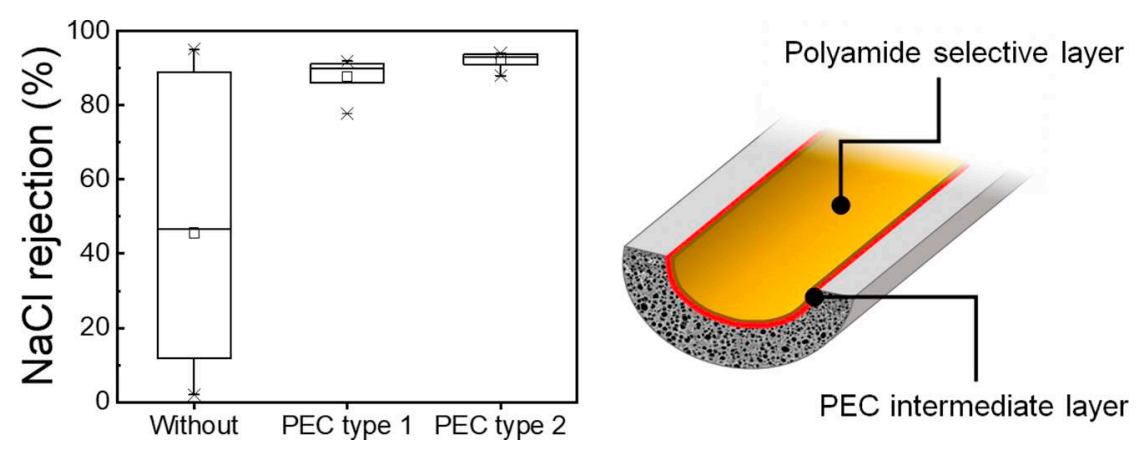

\section{A R T I C L E I N F O}

\section{Keywords:}

Interfacial polymerization

Spinning

Hollow fiber membrane

One-step process

Intermediate layer

\begin{abstract}
A B S T R A C T
In this paper, we introduce a single-step process that incorporates an intermediate layer on a hollow fiber to enhance the final membrane performance after interfacial polymerization (IP). This intermediate layer is applied during hollow-fiber spinning by complexation of two oppositely charged polyelectrolytes. Specifically, in this study, we consider the IP coating process an experimental success for a membrane sample with a $\mathrm{NaCl} \mathrm{rejec-}$ tion $>85 \%$. The IP success rate is defined as the percentage of the samples with a $\mathrm{NaCl}$ rejection of $>85 \%$ within a studied group. The purpose of the intermediate layer is to increase the success rate of IP on the inner surface of the hollow fibers, typically a challenging task due to the cylindrical shape of the fibers. After the application of IP, the pure water permeance and $\mathrm{NaCl}$ rejection of the nascent membranes were tested to determine the success rate of IP. The IP success rate was $86-100 \%$ for the hollow fibers (HF) with intermediate layer, significantly higher than the $29 \%$ success rate achieved for IP on the support without intermediate layer. This surface modification approach is simple, time-efficient, and effective without any need for post-IP optimization that opens up new avenues for further developments for IP based dense hollow fiber membranes.
\end{abstract}

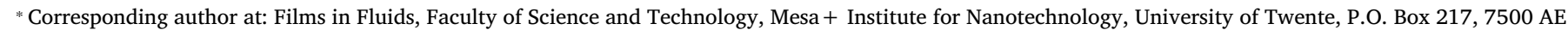
Enschede, the Netherlands.

E-mail address: j.degrooth@utwente.nl (J. de Grooth). 


\section{Introduction}

Ever since the initial development of the interfacial polymerization (IP) on porous structures in the 1970s, it has become the main technique for fabricating polyamide thin-film composite (TFC) membranes for use in desalination [1-8]. The polyamide (PA) layer is formed in situ via a fast reaction between two highly reactive monomers at the interface of two immiscible solvents. The monomers used are a polyfunctional amine dissolved in water and a polyfunctional acid chloride dissolved in an organic solvent such as hexane, isopar E or cyclohexane [9]. Owing to the low solubility of these acid chlorides in water, it is the amine that penetrates into the organic phase to react with the acid chloride $[10,11]$, thus a proper interface is needed to ensure the layer is formed just at the membrane surface. Several parameters such as the specific monomers used, monomer concentration, experimental protocol and choice of solvent $[12,13]$ affect the properties of the nascent PA layer, such as morphology, selectivity, thickness, and chemistry.

For aromatic polyamide TFC membranes, the PA separation layer is typically prepared by the polymerization of $m$-phenylenediamine (MPD) and trimesoyl chloride (TMC) on top of a porous support. It is vital to control the interface between the IP layer and the support as, in addition to the aforementioned parameters, the surface properties like pore size and distribution, porosity, and hydrophilicity also affect the IP process and the final properties of the TFC membrane [14-18].

To increase overall membrane efficiency, the separation layer is often kept as thin as possible as this reduces the overall transport resistance through the separation layer. However, this also increases the likelihood of defects that reduce the water/solute selectivity of the membrane. Louie et al. [19] investigated such defects, and used gas permeation experiments to confirm their presence. In another study [20], small defects were found in several commercial reverse osmosis membranes. Good membrane performance can only be achieved if the coating conditions are optimized for the specific supports and monomers [21] and by varying the MPD and TMC concentrations, the rejection can be increased to above $90 \%$ with higher reproducibility [21]. Ghosh et al. [14] highlighted the importance of pore size in formation of the liquid-liquid interface and showed that small pore size support led to superior salt rejection at the cost of water permeance.

Most TFC membranes are created on flat sheet-type membranes used in spiral wound module configurations. During the IP the liquidliquid interface is relatively easily controlled at the porous support with the aid of gravity. However, in some applications, nonplanar membrane geometries are preferred. For example, the hollow fiber (or tubular) configuration is needed when feed solutions with either high viscosity and/or high concentration of total suspended solids are being filtered [22]. For such hollow fiber (HF) geometries, the application of a TFC layer at the inner surface of HF supports is even more challenging as the liquid-liquid interface cannot be controlled via gravity. This makes the aforementioned trade-off with respect to the pore size ever more relevant. Moreover, local flow, monomer concentration, and pressure distributions within the fiber during application further complicate the application of a thin, defect-free separation layer [[23-25]]. In addition, it is essential to remove any excess MPD drops from the surface. These excess drops will otherwise lead to the low adhesion of the formed layer to the support, eventually resulting in issues such as delamination and pinhole defects [23]. While this can be done easily with a rubber roller for flat sheet supports, this is not possible for HFs. This leads to an uneven monomer distribution and subsequently defects at the liquid-liquid interface. Verissimo et al. [26] tried to resolve this issue (of establishing a proper interface at the inner surface of a fiber) by introducing an organic liquid between the two monomer solutions. Only when this method was applied together with several IP coating optimization steps, a reduction of imperfections (or defects) in the PA layer was achieved. Especially for lower HF diameters $(<1 \mathrm{~mm})$, it becomes difficult to ensure a defect-free membrane, hence commercial TFC-based HF membranes are few and far between. To our knowledge, only $1.5 \mathrm{~mm}$ nanofiltration (NF) membranes were once commercially available [27], but these are now out of production. Tubular TFC membranes are commercially available (e.g. from Berghof Membranes, PCI Membranes), but for many applications, their specific membrane surface-to-volume ratio is not favorable due to the bigger inner diameter ( $>5 \mathrm{~mm}$ ).

The fact that the IP tends to result in defects has led to the difficult and tedious development of better (HF) supports and separation layers. In non-optimized systems, the average selectivity is typically low and displays a large standard deviation (see e.g. [21]). This suggests a nonunimodal distribution of the membrane samples; transport in part of the samples is dominated by transport through pinhole defects. To advance the field, we propose the use of a simple term called the success rate of IP, which allows us to assess prepared membranes samples individually. To this end, we first state that the transport through a membrane sample with a $\mathrm{NaCl}$ rejection $>85 \%$, even when measured at very low flux of $<1\left(\mathrm{~L} \cdot \mathrm{m}^{-2} \cdot \mathrm{h}^{-1}\right)$, is predominantly through the separation layer. If this is the case, we can consider the IP layer process an (experimental) successful coating. We then define the success rate of IP as the percentage of instances with a successful coating.

Several methods have been investigated to improve the reproducibility, and thus the success rate of IP, via surface modification. One approach is to implement a surface modification prior to IP [28-32]. All these surface modifications were performed in an attempt to improve the surface in order to improve the IP reaction as well as the adhesion of the selective layer to the support to prevent delamination. One of the methods for priming the surface for IP is to apply an intermediate layer, which has been investigated in several studies [33-37]. The addition of an intermediate layer fills the pinholes of the support and it yields a smooth layer possibly leading to increased IP success rates. For example, in earlier work, a polyelectrolyte multilayer was utilized as an intermediate layer to increase the IP success rate [37]. Although this method proved to be successful, this method involves a number of timeconsuming post-treatment steps that limit its applicability. Therefore, a faster and more convenient method to increase the success rate and reproducibility of the IP process is still desirable.

In this paper, we present the development of an intermediate layer on the inner surface of HFs in a single-step process. The aim is to increase the success rate of the subsequent IP coating. We hypothesize that the addition of this intermediate layer makes the HF support less prone to defects that develop during IP coating. This, for instance, means that there will be no need for further IP optimization. To this end, two different polyelectrolyte complex (PEC) intermediate layers were produced by ionic cross-linking of the negatively-charged poly(4styrenesulfonic acid) (PSS) with the positively-charged polyethyleneimine (PEI) and poly(diallyldimethylammonium chloride) (PDADMAC). We then evaluate the intermediate layer by scanning electron microscopy and investigate its surface charge and pure water permeance. The IP coating is applied to the inner surface of membranes equipped with two different intermediate layers as well as to hollow fiber membranes without an intermediate layer. The fibers are tested on pure water permeance and $\mathrm{NaCl}$ rejection to evaluate the contribution of the intermediate layer towards the success rate of IP. We will show that the single-step intermediate layer is fully integrated with the support and significantly improved the success rate of the IP reaction.

\section{Experimental}

\subsection{Materials}

Polyimide (PI) Matrimid ${ }^{\circledR} 5218$ from Huntsman (USA) was used as the base polymer for dope solution preparation. Sulfonated PES (SPES) (GM0559/111) was supplied by BASF. The polyelectrolytes utilized in this study were purchased from Sigma (Germany): poly(4-styrenesulfonic acid) (PSS, $\mathrm{Mw} \sim 75,000 \mathrm{~g} \cdot \mathrm{mol}^{-1}, 18 \mathrm{wt} \%$ solution), poly(diallyldimethylammonium chloride) (PDADMAC, $\mathrm{Mw} \sim 400,000-500,000 \mathrm{~g} \cdot \mathrm{mol}^{-1}$, 
Table 1

Bore compositions for the preparation of hollow fibers.

\begin{tabular}{|c|c|c|c|c|c|c|}
\hline Bore solution & $\mathrm{H}_{2} \mathrm{O}(w t \%)$ & NMP (wt\%) & Glycerol (wt\%) & PEG400 (wt\%) & PEI (wt\%) & PDADMAC (wt\%) \\
\hline B1 & 25 & 50 & 25 & - & - & - \\
\hline B2 & 45 & - & 20 & 25 & 10 & - \\
\hline B3 & 45 & - & 20 & 30 & - & 5 \\
\hline
\end{tabular}

$30 \mathrm{wt} \%$ solution), and polyethyleneimine (PEI, Mw $\sim 750,000 \mathrm{~g} \cdot \mathrm{mol}^{-1}$, $50 \mathrm{wt} \%$ solution). Polyethylene glycol (PEG 400, $\mathrm{Mw} \sim 400 \mathrm{~g} \cdot \mathrm{mol}^{-1}$ ) was used as a pore-forming agent and glycerol $86-89 \%$ solution was used as pore-preserving agent, both acquired from Sigma (Germany). The polymer solvent, $N$-methyl-2-pyrrolidone (NMP) $99 \%$, was obtained from Acros Organics (Belgium). For interfacial polymerization, 1,3-phenylenediamine (MPD, > 98\%) was purchased from Merck (USA), 1,3,5-benzenetricarbonyl trichloride (TMC, $>98 \%$ ) was purchased from Sigma, and Isopar E was kindly provided by ExxonMobil Petroleum \& Chemical B.V.B.A (Belgium). All chemicals were used as received without further purification. The PSS $18 \mathrm{wt} \%$ solution was dried prior to use, as was the PI (air oven at $100{ }^{\circ} \mathrm{C}$ for $>24 \mathrm{~h}$ ).

\subsection{Fabrication of hollow-fiber supports}

In this study, the dope solution was a mixture of $16 \mathrm{wt} \% \mathrm{PI}, 2 \mathrm{wt} \%$ SPES, 2 wt $\%$ PSS, 12 wt $\%$ PEG400, and 68 wt $\%$ NMP. Table 1 contains the bore compositions used for spinning. In total, three different types of $\mathrm{HF}$ were fabricated with the dry-jet wet spinning technique (see Table 2). The base-polymer used in this study (PI) was dried in an air oven at $100{ }^{\circ} \mathrm{C}$ for $24 \mathrm{~h}$ prior to dope solution preparation. The dope solution was prepared after placing the bottle containing all compounds on a roller bench overnight for proper mixing. The dope solution was then left in the polymer container of the spinning machine for $48 \mathrm{~h}$ for degassing prior to spinning of the HFs.

The bore solutions were also prepared by mixing all the compounds in bottles on a roller bench overnight. We then left the solutions at room temperature for degassing.

The fibers were spun by using a double orifice spinneret [38]. The dope and bore solutions were pumped to the spinneret via a gear pump, resulting in the extrusion of the HFs. The dope solution, after traversing the air gap, was led into a coagulation bath where the final fiber was formed via non-solvent induced phase separation. Via a pulling wheel, the fibers were transferred in a second bath to be rinsed with water after which the fibers were collected on a pulling wheel. The fibers wound on this wheel were cut and bundled together and subsequently rinsed in deionized (DI) water for $72 \mathrm{~h}$. After this, they were posttreated for $24 \mathrm{~h}$ by immersing them in a $20 \% \mathrm{w} / \mathrm{w}$ glycerol solution to prevent pore collapse during drying. Finally, the fibers were hung for $24 \mathrm{~h}$ to allow them to dry at ambient conditions until further use.

\subsection{Module preparation}

To prepare an HF module, a single fiber was put inside a $8-\mathrm{mm}$ perfluoroalkoxy (PFA) tubing with two QST-8 Festo push-in fittings connected to each side. Both ends were potted by using a 2-component polyurethane adhesive (BISON, $2 \mathrm{~K}$ Expert) resulting in an effective fiber length of $17 \mathrm{~cm}$. Seven modules were prepared for each type of fiber to be used in the pure water permeance and rejection experiments.

\subsection{Membrane characterization}

\subsubsection{Scanning electron microscopy}

The HFs were frozen in liquid nitrogen and fractured to prepare samples for cross-section imaging. To prepare inner surface samples, the fibers were cut diagonally with a sharp razor blade. All samples were stored in a vacuum oven at $30{ }^{\circ} \mathrm{C}$ for $24 \mathrm{~h}$ prior to SEM imaging. Finally, the dried samples were coated with a $10-\mathrm{nm}$ chromium layer with a Quorum Q150T ES sputter coater, before microscopy was carried out with a JEOL JSM-6010LA SEM.

\subsubsection{Zeta potential determination}

We determined the zeta potential of the fibers a SurPASS electrokinetic analyzer (Anton Paar, Graz Austria) at a pH range of 3-11 and $5 \mathrm{mM} \mathrm{KCl}$ as the electrolyte solution. For this purpose, three fibers from each batch were potted in three 7-cm lengths of tubing. The zeta potential was measured six times for each set value of $\mathrm{pH}$ (see Section 3.2). The $\mathrm{pH}$ was adjusted by automatic titration, with $0.1 \mathrm{M} \mathrm{HCl}$ and $0.1 \mathrm{M} \mathrm{NaOH}$. We calculated the zeta potential with Eq. 1 . In the end, the average of all measured zeta potentials versus $\mathrm{pH}$ is plotted for each type of fiber.

$\zeta=\frac{\mathrm{dI}}{\mathrm{dP}} \frac{\eta}{\varepsilon \varepsilon_{0}} \frac{\mathrm{L}_{\mathrm{s}}}{\mathrm{A}_{\mathrm{s}}}$

where $\zeta$ is the zeta potential $(\mathrm{V}), \mathrm{I}$ is the streaming current $(\mathrm{A}), \mathrm{P}$ is the pressure $(\mathrm{Pa}), \eta$ is the dynamic viscosity of the electrolyte solution (Pas), $\varepsilon$ is the dielectric permittivity of the water, $\varepsilon_{0}$ is the dielectric permittivity in vacuum ( $F \cdot m^{-1}$ ), $L_{s}$ is the channel length (m), and $A_{s}$ is the cross-section of the streaming channel $\left(\mathrm{m}^{2}\right)$.

\subsubsection{Pure water permeance measurement}

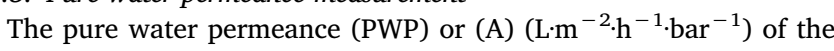
fibers was measured by flowing DI water inside the fibers in dead-end mode at a nitrogen pressure of 2 bar.

$\mathrm{A}=\frac{\mathrm{V}}{\mathrm{t} \mathrm{A} \Delta \mathrm{P}}$

In this equation, $\mathrm{V}$ is the volume of collected permeates (L), $\mathrm{t}$ is the collecting time $(\mathrm{h}), \mathrm{A}$ is the membrane inner surface area $\left(\mathrm{m}^{2}\right)$, and $\Delta \mathrm{P}$ is the pressure difference between the bore and the shell of the HFs (bar).

Additionally, the membrane resistances are determined based on Darcy's law [39] and used for a resistance in series approximation:

$\mathrm{R}_{\mathrm{T}}=\frac{1000}{\mu \mathrm{A}}=\mathrm{R}_{\mathrm{S}}+\mathrm{R}_{\mathrm{IP}}$

where $R_{T}$ is the total membrane resistance, $R_{S}$ is the resistance of the

Table 2

Spinning conditions for the preparation of hollow fibers. For bore codes, see Table 1 .

\begin{tabular}{|c|c|c|c|c|c|c|c|c|}
\hline Membrane code & Bore code & Dope temperature $\left({ }^{\circ} \mathrm{C}\right)$ & $\begin{array}{l}\text { Dope flow rate (mL/ } \\
\text { min) }\end{array}$ & $\begin{array}{l}\text { Bore flow rate (mL/ } \\
\text { min) }\end{array}$ & $\begin{array}{l}\text { Take-up speed (m/ } \\
\text { min) }\end{array}$ & $\begin{array}{l}\text { Air gap length } \\
(\mathrm{cm})\end{array}$ & Humidity (\%) & Temp. $\left({ }^{\circ} \mathrm{C}\right)$ \\
\hline PI-REF & B1 & 65 & 3.9 & 3 & 2.4 & 10 & 31 & 22.5 \\
\hline PI-PEI & B2 & 65 & 3.9 & 3 & 2.4 & 10 & 31 & 22.5 \\
\hline PI-PDA & B3 & 65 & 3.9 & 3 & 2.4 & 10 & 31 & 22.5 \\
\hline
\end{tabular}


hollow fiber support, $\mathrm{R}_{\mathrm{IP}}$ the resistance of the IP layer (all in $\mathrm{m}^{-1}$ ), and $\mu$ is the water viscosity at $25{ }^{\circ} \mathrm{C}\left(2.47 \times 10^{-12}\right.$ barh $)$.

\subsubsection{Salt rejection}

$\mathrm{HF}$ membrane rejection towards $500 \mathrm{ppm} \mathrm{NaCl}$ solution was determined in an inside-out cross-flow filtration system at a transmembrane pressure (TMP) of 2 bar. The rejection was calculated with Eq. (4) by measuring the conductivity of the feed solution and collected permeate. The cross-flow rate in each fiber was set to $2 \mathrm{~L} \cdot \mathrm{h}^{-1}$.

$\mathrm{R}=\frac{\left(\sigma_{\mathrm{f}}-\sigma_{\mathrm{p}}\right)}{\sigma_{\mathrm{f}}} \times 100$

In this equation, $\mathrm{R}$ is the salt rejection percentage (\%), $\sigma_{\mathrm{f}}$ is the conductivity of feed solution $\left(\mu S \cdot \mathrm{cm}^{-1}\right)$, and $\sigma_{\mathrm{p}}$ is the conductivity of the permeate solution $\left(\mu S \cdot \mathrm{cm}^{-1}\right)$. The salt permeance (B) were determined after Yip et al. [40], with a mass transfer coefficient according to the Lévêque correlation for a fully developed laminar velocity profile in a tube [41].

\subsubsection{Molecular weight cut-off estimation}

The molecular weight cut-off (MWCO) of the fibers was determined by using two solutions containing a mixture of different poly(ethylene glycol) (PEG) molecules. The first mixture contained PEGs with a molecular range of 62-2000 g.mol ${ }^{-1}$, while the second had PEGs with a molecular range of 4000-35,000 g.mol ${ }^{-1}$. The solutions were filtered in an inside-out configuration at the TMP and cross-flow that were also used in the rejection tests: 2 bar and $2 \mathrm{~L} \cdot \mathrm{h}^{-1}$, respectively. The MWCO of a membrane is defined as the molecular weight at which a molecule is retained for $90 \%$. To analyze the feed and permeate samples, we used a gel permeation chromatograph (GPC), which was equipped with a size exclusion column (Agilent 1200/1260 Infinity GPC/SEC series). The samples were fed at $1 \mathrm{~mL} \cdot \mathrm{min}^{-1}$ to column of $1000 \AA$, $10 \mu \mathrm{m}$ and a column of $30 \AA, 10 \mu \mathrm{m}$. The PEG concentrations were determined via refractive index measurements.

\subsubsection{Interfacial polymerization}

Interfacial polymerization (MPD and TMC) was performed on the inner surface of the fibers. Prior to the reaction, all modules were immersed in DI water overnight to remove the glycerol storage solution. The MPD solution was prepared by dissolving the desired amount of MPD in DI water to obtain a $2.5 \%(\mathrm{w} / \mathrm{v})$ solution. The $0.15 \%(\mathrm{w} / \mathrm{v})$ TMC solution was prepared by dissolving TMC in Isopar E in a preheated $\left(70{ }^{\circ} \mathrm{C}, 15 \mathrm{~min}\right)$ bottle to prevent crystallization of TMC and to evaporate any residual moisture.

Then, firstly, excess water in the inner and outer surface of the HF was removed by a $\mathrm{N}_{2}$-flow for $45 \mathrm{~s}$ at each inlet. MPD solution was then fed from bottom into the bore side of the vertically-fixed fiber by using a syringe pump at $2 \mathrm{~mL} \cdot \mathrm{min}^{-1}$ for $2 \mathrm{~min}$. Next, the solution was kept inside the fiber in a horizontal position for $6 \mathrm{~min}$ followed by the removal of excess MPD by $\mathrm{N}_{2}$-flow for $150 \mathrm{~s}$. Subsequently, TMC solution was introduced from the bottom into the vertically-fixed fiber by using a syringe pump at $2 \mathrm{~mL} \cdot \mathrm{min}^{-1}$ for two times $15 \mathrm{~s}$ with an interval of $45 \mathrm{~s}$. Finally, the TMC residue was removed by $\mathrm{N}_{2}$-flow for $30 \mathrm{~s}$ followed by rinsing the fibers with $20 \mathrm{~mL}$ of $\mathrm{DI}$ water.

\section{Results and discussion}

\subsection{Hollow-fiber characteristics}

Table 3 lists the fibers' dimension and their MWCO. The MWCO was measured for the two types of fiber with the intermediate layer (PI-PEI and PI-PDA) before the application of the IP coating. Because of the large pores of PI-REF, it was not possible to determine its MWCO with the PEG solutions used for MWCO experiment. Both PI-PEI and PI-PDA showed an MWCO similar to that of NF membranes, which indicates the existence of a dense layer coated in the inner surface of the HF supports.
Table 3

Characteristics of the hollow fibers (inner diameter, outer diameter, and MWCO).

\begin{tabular}{llll}
\hline Membrane & $\begin{array}{l}\text { Inner diameter (ID) } \\
(\mathrm{mm})\end{array}$ & $\begin{array}{l}\text { Outer diameter (OD) } \\
(\mathrm{mm})\end{array}$ & MWCO (kDa) \\
\hline PI-REF & $0.90 \pm 0.01$ & $1.26 \pm 0.10$ & $>35,000$ \\
PI-PEI & $0.90 \pm 0.02$ & $1.30 \pm 0.01$ & $2.0 \pm 0.30$ \\
PI-PDA & $0.88 \pm 0.04$ & $1.20 \pm 0.01$ & $0.71 \pm 0.01$ \\
\hline
\end{tabular}

Fig. 1 presents SEM images of the inner surface of three fibers before (left) and after (right) IP coating. All three IP coated membranes clearly revealed a typical ridge-and-valley PA layer on their inner surface but no defects could be detected in the SEM images. This is expected as SEM imaging targets only a small location, which can be free of defects. Alternatively, defects may be very tiny and undetectable with the used imaging technique. Therefore, defects (e.g. pinholes) are usually detected by running the PWP and rejection tests and measuring the separation layer resistance against water and $\mathrm{NaCl}$.

Fig. 2 shows cross-section images of the bore side of the fibers. The intermediate layer of the PI-PEI fiber is rather thin and embedded within the support and can therefore not be identified very well, while the intermediate layer of the PI-PDA fiber is slightly thicker and therefore more obvious, but also appears fully integrated into the support's structure (Section 3.2 discusses the degree of integration of the intermediate layer in the support structure on the basis of the zeta potential results). No clear differences between the PI-REF and PI-PEI images in terms of morphology and thickness of the PA layer post-IP are visible, while a more pronounced PA layer can be seen for PI-PDA.

\subsection{Zeta potential of fibers before IP}

The zeta potential of the surface of the fibers was evaluated pre-IP and is plotted in Fig. 3. Both PI-PEI and PI-PDA possessed a more partly positive zeta potential relative to PI-REF which showed a negative zeta potential for the whole $\mathrm{pH}$ range. This positive charge is due to the presence of the positively-charged PEI and PDADMAC in the intermediate layers of PI-PEI and PI-PDA fibers, respectively. The different zeta potential profile of these two fibers relative to the PI-REF fiber proves the existence of the intermediate layer. However, these zeta potential profiles do not follow those of pure PEI or PDADMAC as both pure PEI and PDADMAC would have shown a positive zeta potential over a wider $\mathrm{pH}$-range and an isoelectric point above $\mathrm{pH}$ 9.5. This is because PDADMAC is a permanently positively charged polyelectrolyte regardless of $\mathrm{pH}$ [42] and $\mathrm{PEI}$ shows a positive zeta potential in the $\mathrm{pH}$ range of 3-10 [43]. The $\mathrm{pH}$ dependency observed here for the two fibers with an intermediate layer (PI-PEI and PI-PDA) suggests that the support polymer (PI) still contributes to the final zeta potential of these two membranes. This indicates that the used preparation procedure (single-step spinning) resulted in the proper embedding of the intermediate layer in the support structure. This integration is wanted as it prevents possible delamination of the intermediate layer. It is also worth to mention that the less positive surface and the lower isoelectric point acquired for PI-PDA as compared to PI-PEI can be attributed to the lower charge density of PDADMAC as compared to PEI [44].

\subsection{Pure water permeance}

The pure water permeance (PWP) of the fibers was measured for both pre-IP and post-IP fibers (Fig. 4). The purpose of the pre-IP measurement was to evaluate the effect of the intermediate layer for the PIPEI and PI-PDA fibers compared with the PI-REF fibers (Fig. 4a). The PIREF fibers had a water permeance of $60 \pm 15\left(\mathrm{~L} \cdot \mathrm{m}^{-2} \cdot \mathrm{h}^{-1} \cdot \mathrm{bar}^{-1}\right)$ preIP but this was much lower at $2.3 \pm 1.3\left(\mathrm{~L}^{-2} \mathrm{~m}^{-1} \cdot \mathrm{bar}^{-1}\right)$ and $1.2 \pm 0.8\left({\mathrm{~L} \cdot \mathrm{m}^{-2}}^{-1} \mathrm{~h}^{-1} \cdot \mathrm{bar}^{-1}\right)$ for PI-PEI and PI-PDA, respectively. This 

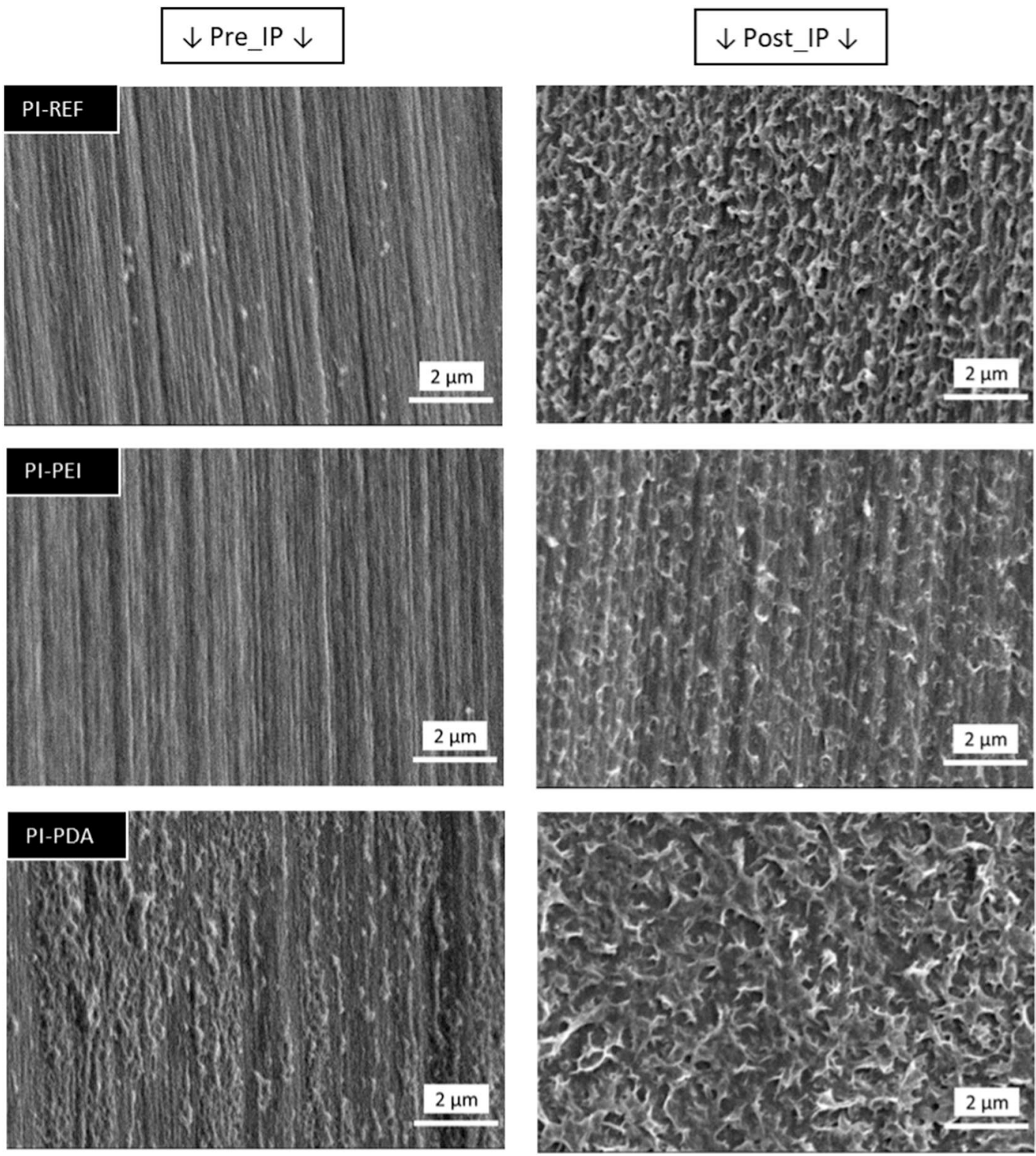

Fig. 1. SEM images of the surface of the inner surface of three fibers before and after IP coating, taken at a magnification of $10,000 \times$.

reduction in PWP is another confirmation of the existence of an intermediate layer for the PI-PEI and PI-PDA fibers; it results from the additional transport resistance of the intermediate layer for water.

We also evaluated the effect of the intermediate layer on the successful prevention of defects via measuring of the post-IP PWP (Fig. 4b). The average PWP after IP coating decreased to 2.65, 0.32, and 0.28 $\left(\mathrm{L} \cdot \mathrm{m}^{-2} \cdot \mathrm{h}^{-1} \cdot \mathrm{bar}^{-1}\right)$ for PI-REF, PI-PEI, and PI-PDA, respectively, indicating that a PA layer indeed had formed. This is in agreement with the SEM imaging results. However, PWP test revealed the presence of defects which were not detectable by SEM. For the support without an intermediate layer, we observed a large degree of scatter, indicating a low reproducibility of the IP process as a result of the development of pinhole defects. By contrast, the two types of fibers with an intermediate layer showed very little deviation between samples. This low spread in the PWP results indicates that a much more consistent (defectfree) layer formed when we applied our procedure. In other words, the presence of the intermediate layer increased the success rate of IP in the inner surface of the HFs. Similar results were found by Ormanci-Acar et al. [37] where the addition of 3.5 polyelectrolyte bilayers as intermediate layer helped to improve the IP results.

Additionally, the IP layer resistance was determined for the membranes with and without an intermediate layer (Fig. 5). For this, the total resistance of the membrane before IP (with $R_{T}=R_{I P}$ ) was subtracted from the total membrane resistance after IP. The results show that the IP layer resistances of the PI-PEI and PI-PDA membranes are very similar, while the resistance of the IP layer is substantially lower for the PI-REF. This similarity of the resistances of both membrane types with an intermediate layer demonstrates that the type of intermediate layer does not severely influence the formed IP layer with respect to cross-linking density and thickness. The obtained resistances for the IP layers on the supports with an intermediate layer are very much comparable to those found for conventional membranes [39,45]. Moreover, the lower resistance on average for membranes without intermediate layer (PI-REF) is indicative for the defects present in this layer. Furthermore, the two samples from the PE-REF membranes with a substantially higher resistance did both also show a high $\mathrm{NaCl}$ retention. 

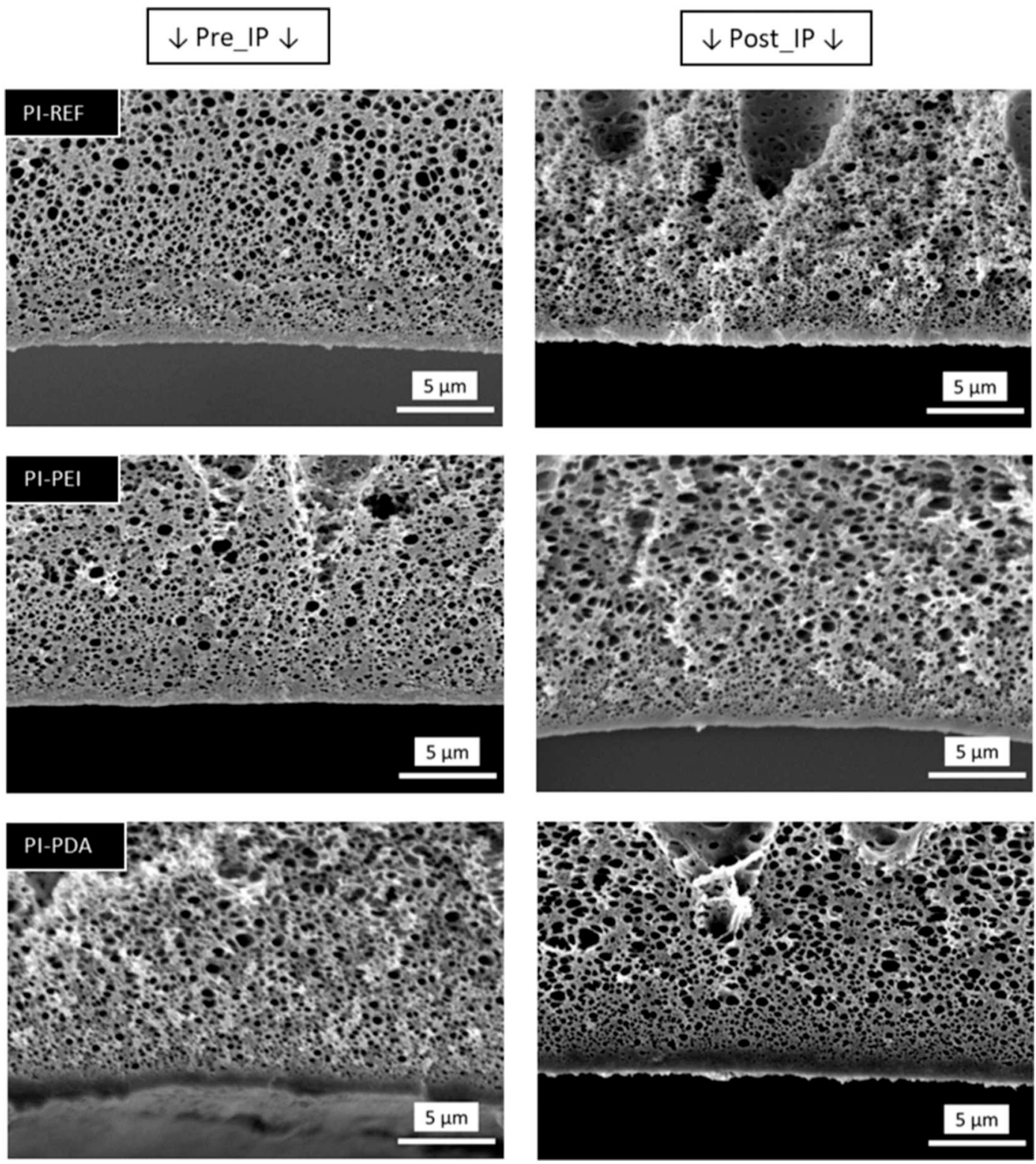

Fig. 2. Cross-section SEM images of the bore of three fibers before and after IP coating, taken at a magnification of $5000 \times$.

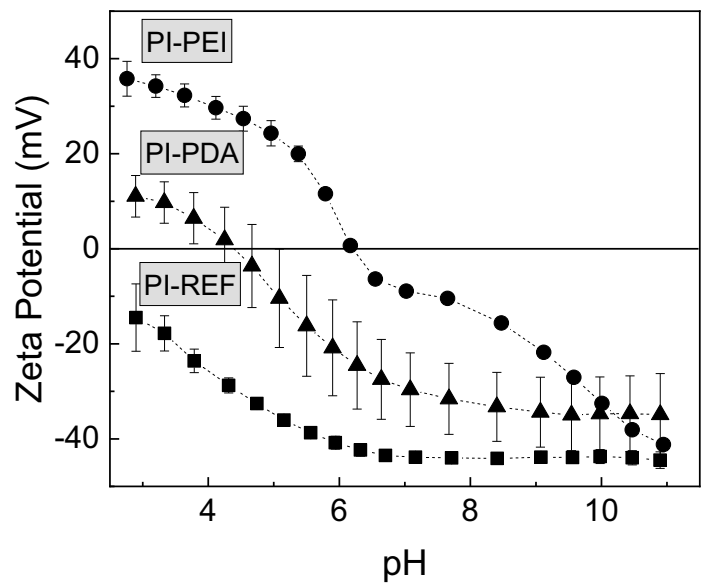

Fig. 3. Zeta potential of the three fibers as a function of $\mathrm{pH}$. Results are an average of six measurements for each sample.

\subsection{Salt rejection}

To further show the effect of defects, we determined the $\mathrm{NaCl}$ rejection by means of a filtration experiment of individually coated membranes (Fig. 6). The results were also used to assess the success rate of IP. The two types of HF support equipped with an intermediate layer had already showed a slight $\mathrm{NaCl}$ rejection before IP coating due to the charged polyelectrolyte complex [46]. This was $14 \pm 6 \%$ for PI-PEI and $27 \pm 9 \%$ for PI-PDA.

As can be seen in Fig. 6, the $\mathrm{NaCl}$ rejection for the membranes without the intermediate layer (PI-REF) was scattered between 10 and $90 \%$, reflecting a highly irreproducible coating process. This clearly showed that in many cases, the transport was also governed by transport through pinholes. This translates into a success rate of only $29 \%$ for the IP coating. In contrast, the $\mathrm{NaCl}$ rejection significantly increased for all samples for the two types of fibers with an intermediate layer. In addition, much less scattering was seen between the samples. This shows that a far more reproducible coating process can be obtained after application of an intermediate layer. In fact, the success rate was determined to be $86 \%$ for PI-PEI and as high as $100 \%$ for PI-PDA. 

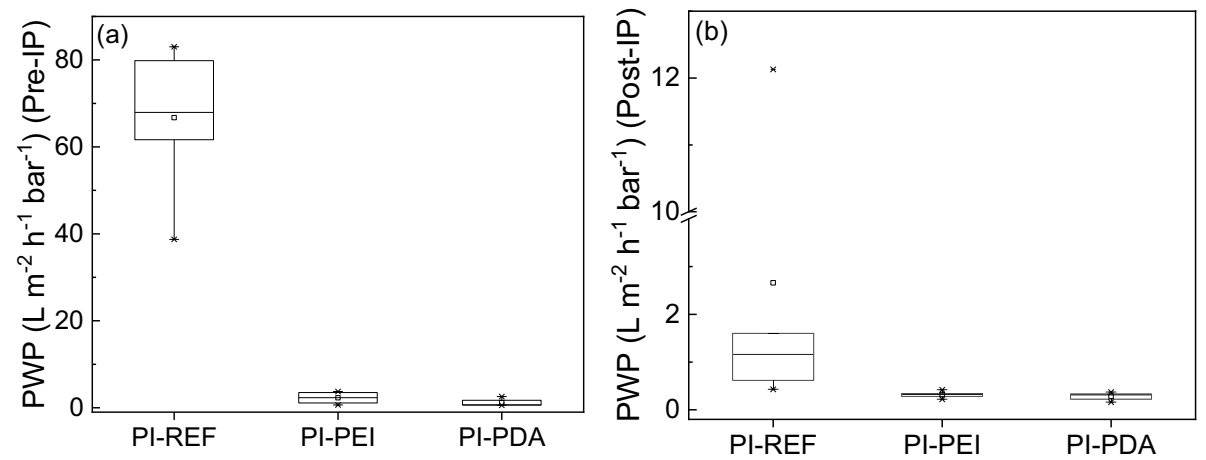

Fig. 4. Pure water permeance measured at 2 bar in dead-end configuration for the three types of fiber a) Pre-IP and b) Post-IP coating (based on seven fibers coated, each tested separately).

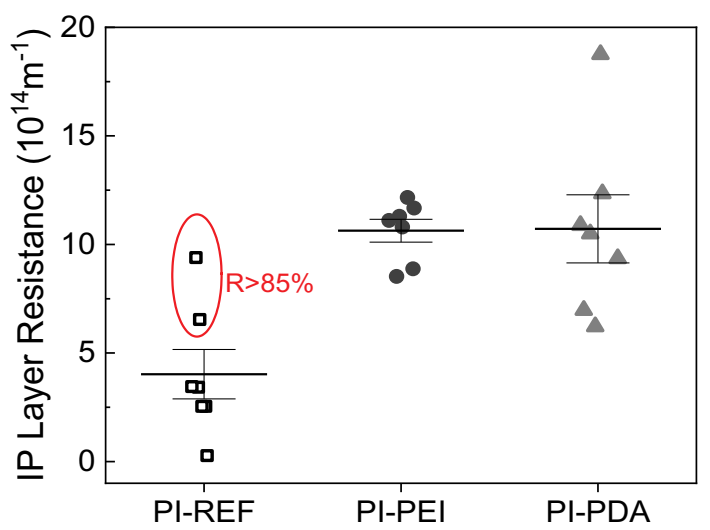

Fig. 5. The IP layer resistance $\left(\mathrm{R}_{\mathrm{IP}}\right)$, determined using an resistance in series approximation.

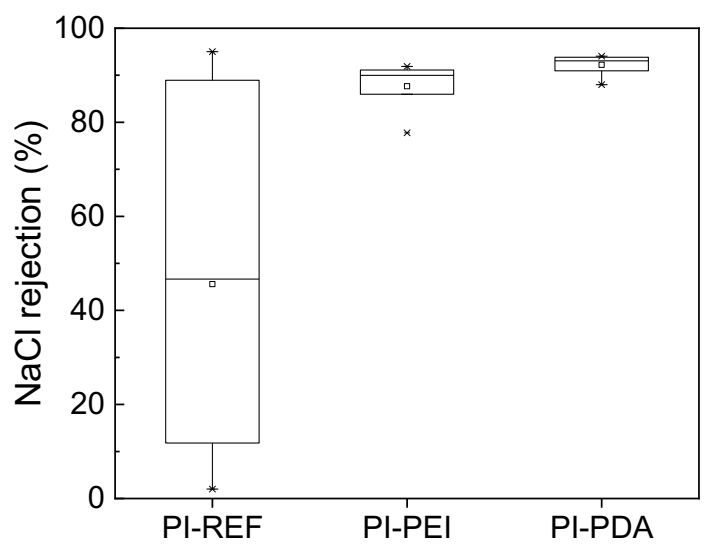

Fig. 6. NaCl rejection of the fibers after IP coating at a transmembrane pressure of 2 bar and a cross-flow of $2 \mathrm{~L} \cdot h^{-1}$ (seven individually coated and tested modules for each of fiber types).

To investigate whether the rejection results achieved for the supports with an intermediate layer (PI-PEI and PI-PDA) were indeed significantly different than those for PI-REF (without intermediate layer), we performed a statistical analysis on the results. Our hypothesis is that, due to the effect of an intermediate layer, the variances between samples coated with and without PEC are unequal and that a higher rejection is obtained by samples with a PEC intermediate layer. For this, a one-tailed Welch's $t$-test can be used that tests the null hypothesis that two populations with unequal variance have equal means [47]. We used the standard alpha level (or significance level) of 0.05 (Table 4).

The results clearly show an unequal variance between the PI-REF coated membranes and the PEC based membranes. The higher variance
Table 4

Welch's $t$-test results.

\begin{tabular}{|c|c|c|c|c|}
\hline \multicolumn{3}{|c|}{ Variance } & \multicolumn{2}{|c|}{ One-tailed $t$-test results } \\
\hline PI-REF & PI-PEI & PI-PDA & PI-REF vs. PI-PEI & PI-REF vs. PI-PDA \\
\hline \multirow[t]{2}{*}{1316} & 20 & 4.0 & $t=3.04$ & $t=3.40$ \\
\hline & & & $\begin{array}{l}\mathrm{t}_{\text {critical }}=1.94 \\
P=.011\end{array}$ & $\begin{array}{l}\mathrm{t}_{\text {critical }}=1.94 \\
P=.007\end{array}$ \\
\hline
\end{tabular}

of the membranes without a PEC intermediate layer is in agreement with the low success rate of coating and indicates that indeed the formation of the TFC separation layer is more erratic without an intermediate layer. Furthermore, for both cases, the t-values are higher than t-critical. This means the null hypothesis can be rejected, implying that the different populations do not have an equal mean. This shows that the samples with a PEC intermediate layer have a statistical higher $\mathrm{NaCl}$ rejection with a lower variation. An analysis between the two different populations with either PEI or PDA as intermediate layer, showed that these two membrane types do not show a different mean based on a two-tailed Welch's $t$-test $\left(t=2.25, \mathrm{t}_{\text {critical }}=2.31, P=.027\right)$. Although there is no apparent difference between the performance of the two different PEC-based membranes, it can be argued that long-term performance could give a preference to the PEI based membranes as PEI has the ability to also participate in the IP reaction, covalently attaching the IP layer to the PEC support.

In addition, the water permeance (A, horizontal axis) of the different membranes is plotted against their selectivity (A/B, vertical axis) for each individual fiber (Fig. 7). This is a common way to indicate the trade-off between water permeance and salt selectivity [48]. What

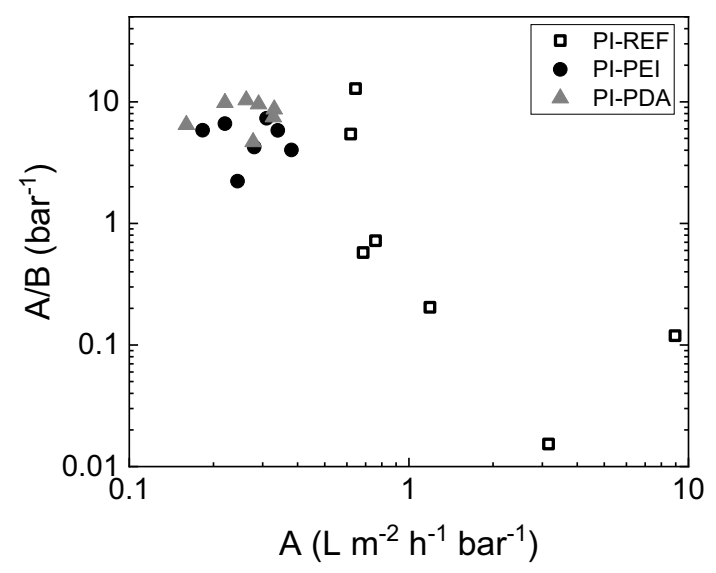

Fig. 7. Water permeance (A) versus salt permeance (B) of the three types of fibers as determined from $\mathrm{NaCl}$ rejection tests. 
becomes evident is that for the membranes with an intermediate layer, the PEC layer does not add to the selectivity of the membrane. In fact, for these samples, it seems that the intermediate layer, while increasing the success rate, also increases the overall transport resistance. The membranes without an intermediate layer, clearly show a permeance/ selectivity trade-off that can be attributed to the presence of defects in the separation layer. This trade-off is similar to that observed with TFC membranes [45,49].

All in all, we show that the existence of the intermediate layer increases the success rate and reproducibility of the IP coating significantly as compared to the fibers without an intermediate layer. This was tested experimentally and supported by a statistical analysis. As this paper was exclusively aimed towards the proof of concept of increasing the IP success rate by the addition of an intermediate layer, a high concentration of polyelectrolytes was used in the spinning solutions. This inherently led to a relatively low starting permeance before IP coating impairing the final permeance of the membranes. However, we note that the water permeance (A) of the final fibers coated with an intermediate layer can be substantially improved e.g. by lowering the concentration of the polyelectrolyte in the spinning solutions in order to produce thinner intermediate layers.

\section{Conclusions}

This study presents a single-step approach for increasing the success rate of interfacial polymerization based selective layers when applied on the inner surface of hollow fibers used for desalination purposes. For this, an intermediate layer is directly applied during the membrane formation which prevents detrimental defects on the inner surface of the fibers and as such no further IP optimization step is needed to obtain a defect free layer per se.

Two different types of fiber, with a different intermediate layer (either PI-PEI or PI-PDA) were fabricated. After IP, these two fibers had a lower PWP as well as less variance compared with their counterparts without intermediate layer (PI-REF). Additionally, a higher $\mathrm{NaCl}$ rejection, on average, was achieved for both membranes with intermediate layer with, again, little variation. We defined the IP success rate for membranes used for desalination purposes as the percentage of membranes with an $\mathrm{NaCl}$ rejection higher than $85 \%$. This success rate for PI-PEI and PI-PDA was $86 \%$ and $100 \%$, respectively, while this was as low as $29 \%$ for PI-REF.

Further improvements will be needed to optimize the thickness and density of the intermediate layer in order to lower its overall resistance towards water transport. This can, for instance, be simply achieved by lowering the polyelectrolyte concentration. This method allows for a much easier application of an IP based separation layer and opens up new avenues for the development of desalination membranes with different, nonplanar, geometries.

\section{CRediT authorship contribution statement}

M. Mohammadifakhr: Methodology, Conceptualization, Investigation, Writing - original draft. K. Trzaskus: Methodology, Conceptualization. A.J.B. Kemperman: Supervision, Writing - review \& editing. H.D.W. Roesink: Funding acquisition, Writing - review \& editing. J. de Grooth: Funding acquisition, Formal analysis, Supervision, Writing - review \& editing.

\section{Declaration of competing interest}

Dr. K. Trzaskus currently holds a position at Aquaporin A/S. This company partly funded the project as part of the Top Technology Twente: UT impulse program.

\section{Acknowledgments}

The project was funded by Aquaporin A/S and the Top Technology Twente: UT Impulse Program for which the authors are very grateful.

\section{References}

[1] B.-H. Jeong, E.M.V. Hoek, Y. Yan, A. Subramani, X. Huang, G. Hurwitz, A.K. Ghosh, A. Jawor, Interfacial polymerization of thin film nanocomposites: a new concept for reverse osmosis membranes, J. Membr. Sci. 294 (2007) 1-7, https://doi.org/10. 1016/j.memsci.2007.02.025.

[2] J.E. Cadotte, R.J. Petersen, R.E. Larson, E.E. Erickson, A new thin-film composite seawater reverse osmosis membrane, Desalination 32 (1980) 25-31, https://doi. org/10.1016/S0011-9164(00)86003-8.

[3] J.E. Cadotte, L.T. Rozelle, In-Situ Formed Condensation Polymers for Reverse Osmosis Membranes, OSW PB-Rep, 1972.

[4] A.W. Mohammad, Y.H. Teow, W.L. Ang, Y.T. Chung, D.L. Oatley-Radcliffe, N. Hilal, Nanofiltration membranes review: recent advances and future prospects, Desalination 356 (2015) 226-254, https://doi.org/10.1016/j.desal.2014.10.043.

[5] N. Misdan, W.J. Lau, A.F. Ismail, Seawater reverse osmosis (SWRO) desalination by thin-film composite membrane-current development, challenges and future prospects, Desalination 287 (2012) 228-237, https://doi.org/10.1016/j.desal.2011.11. 001.

[6] J.E. Cadotte, Interfacially synthesized reverse osmosis membrane, US Patent 4,277, 344, (1981).

[7] A. Prakash Rao, N.V. Desai, R. Rangarajan, Interfacially synthesized thin film composite RO membranes for seawater desalination, J. Membr. Sci. 124 (1997) 263-272, https://doi.org/10.1016/S0376-7388(96)00252-9.

[8] K.P. Lee, T.C. Arnot, D. Mattia, A review of reverse osmosis membrane materials for desalination-development to date and future potential, J. Membr. Sci. 370 (2011) 1-22, https://doi.org/10.1016/j.memsci.2010.12.036.

[9] A.K. Ghosh, B.-H. Jeong, X. Huang, E.M.V. Hoek, Impacts of reaction and curing conditions on polyamide composite reverse osmosis membrane properties, J. Membr. Sci. 311 (2008) 34-45, https://doi.org/10.1016/j.memsci.2007.11.038.

[10] V. Freger, Kinetics of film formation by interfacial polycondensation, Langmuir 21 (2005) 1884-1894, https://doi.org/10.1021/la048085v.

[11] P.W. Morgan, S.L. Kwolek, Interfacial polycondensation. II. Fundamentals of polymer formation at liquid interfaces, J. Polym. Sci. 40 (1959) 299-327, https:// doi.org/10.1002/pol.1959.1204013702.

[12] W. Xie, G.M. Geise, B.D. Freeman, H.S. Lee, G. Byun, J.E. McGrath, Polyamide interfacial composite membranes prepared from m-phenylene diamine, trimesoyl chloride and a new disulfonated diamine, J. Membr. Sci. 403-404 (2012) 152-161, https://doi.org/10.1016/j.memsci.2012.02.038.

[13] E.L. Wittbecker, P.W. Morgan, Interfacial polycondensation. I, J. Polym. Sci. 40 (1959) 289-297, https://doi.org/10.1002/pol.1959.1204013701.

[14] A.K. Ghosh, E.M.V. Hoek, Impacts of support membrane structure and chemistry on polyamide-polysulfone interfacial composite membranes, J. Membr. Sci. 336 (2009) 140-148, https://doi.org/10.1016/j.memsci.2009.03.024.

[15] L. Huang, J.R. McCutcheon, Impact of support layer pore size on performance of thin film composite membranes for forward osmosis, J. Membr. Sci. 483 (2015) 25-33, https://doi.org/10.1016/j.memsci.2015.01.02.

[16] N. Misdan, W.J. Lau, A.F. Ismail, T. Matsuura, Formation of thin film composite nanofiltration membrane: effect of polysulfone substrate characteristics, Desalination 329 (2013) 9-18, https://doi.org/10.1016/j.desal.2013.08.021.

[17] N. Misdan, W.J. Lau, A.F. Ismail, T. Matsuura, D. Rana, Study on the thin film composite poly(piperazine-amide) nanofiltration membrane: impacts of physicochemical properties of substrate on interfacial polymerization formation, Desalination 344 (2014) 198-205, https://doi.org/10.1016/j.desal.2014.03.036.

[18] J.-A.-D. Sharabati, S. Guclu, S. Erkoc-Ilter, D.Y. Koseoglu-Imer, S. Unal, Y.Z. Menceloglu, I. Ozturk, I. Koyuncu, Interfacially polymerized thin-film composite membranes: impact of support layer pore size on active layer polymerization and seawater desalination performance, Sep. Purif. Technol. 212 (2019) 438-448, https://doi.org/10.1016/j.seppur.2018.11.047.

[19] J.S. Louie, I. Pinnau, M. Reinhard, Effects of surface coating process conditions on the water permeation and salt rejection properties of composite polyamide reverse osmosis membranes, J. Membr. Sci. 367 (2011) 249-255, https://doi.org/10.1016/ j.memsci.2010.10.067.

[20] J.S. Louie, I. Pinnau, M. Reinhard, Gas and liquid permeation properties of modified interfacial composite reverse osmosis membranes, J. Membr. Sci. 325 (2008) 793-800, https://doi.org/10.1016/j.memsci.2008.09.006.

[21] C. Klaysom, S. Hermans, A. Gahlaut, S. Van Craenenbroeck, I.F.J. Vankelecom, Polyamide/Polyacrylonitrile (PA/PAN) thin film composite osmosis membranes: film optimization, characterization and performance evaluation, J. Membr. Sci. 445 (2013) 25-33, https://doi.org/10.1016/j.memsci.2013.05.037.

[22] P.A. Pedersen, F.B. Bjørkskov, S. Alvisse, C. Hélix-Nielsen, From channel proteins to industrial biomimetic membrane technology, Faraday Discuss. 209 (2018) 287-301, https://doi.org/10.1039/C8FD00061A.

[23] W.J. Lau, A.F. Ismail, N. Misdan, M.A. Kassim, A recent progress in thin film composite membrane: a review, Desalination 287 (2012) 190-199, https://doi.org/ 10.1016/j.desal.2011.04.004.

[24] A.P. Korikov, P.B. Kosaraju, K.K. Sirkar, Interfacially polymerized hydrophilic microporous thin film composite membranes on porous polypropylene hollow fibers and flat films, J. Membr. Sci. 279 (2006) 588-600, https://doi.org/10.1016/j. memsci.2005.12.051. 
[25] S.-H. Yoon, S. Lee, I.-T. Yeom, Experimental verification of pressure drop models in hollow fiber membrane, J. Membr. Sci. 310 (2008) 7-12, https://doi.org/10.1016/ j.memsci.2007.11.048.

[26] S. Veríssimo, K.-V. Peinemann, J. Bordado, Thin-film composite hollow fiber membranes: an optimized manufacturing method, J. Membr. Sci. 264 (2005) 48-55, https://doi.org/10.1016/j.memsci.2005.04.020.

[27] H. Futselaar, H. Schonewille, W. van der Meer, Direct capillary nanofiltration - a new high-grade purification concept, Desalination 145 (2002) 75-80, https://doi. org/10.1016/S0011-9164(02)00389-2.

[28] C.-H. Yu, I. Kusumawardhana, J.-Y. Lai, Y.-L. Liu, PTFE/polyamide thin-film composite membranes using PTFE films modified with ethylene diamine polymer and interfacial polymerization: preparation and pervaporation application, J. Colloid Interface Sci. 336 (2009) 260-267, https://doi.org/10.1016/j.jcis.2009.03.052.

[29] N.-W. Oh, J. Jegal, K.-H. Lee, Preparation and characterization of nanofiltration composite membranes using polyacrylonitrile (PAN). II. Preparation and characterization of polyamide composite membranes, J. Appl. Polym. Sci. 80 (2001) 2729-2736, https://doi.org/10.1002/app.1387.

[30] J. Peng, Y. Su, W. Chen, X. Zhao, Z. Jiang, Y. Dong, Y. Zhang, J. Liu, C. Xingzhong, Polyamide nanofiltration membrane with high separation performance prepared by EDC/NHS mediated interfacial polymerization, J. Membr. Sci. 427 (2013) 92-100, https://doi.org/10.1016/j.memsci.2012.09.039.

[31] H. Il Kim, S.S. Kim, Plasma treatment of polypropylene and polysulfone supports for thin film composite reverse osmosis membrane, J. Membr. Sci. 286 (2006) 193-201, https://doi.org/10.1016/j.memsci.2006.09.037.

[32] Y. Li, Y. Su, J. Li, X. Zhao, R. Zhang, X. Fan, J. Zhu, Y. Ma, Y. Liu, Z. Jiang, Preparation of thin film composite nanofiltration membrane with improved structural stability through the mediation of polydopamine, J. Membr. Sci. 476 (2015) 10-19, https://doi.org/10.1016/j.memsci.2014.11.011.

[33] A.A.M. Salih, C. Yi, H. Peng, B. Yang, L. Yin, W. Wang, Interfacially polymerized polyetheramine thin film composite membranes with PDMS inter-layer for $\mathrm{CO} 2$ separation, J. Membr. Sci. 472 (2014) 110-118, https://doi.org/10.1016/j.memsci. 2014.08.025.

[34] W. Zhao, H. Liu, Y. Liu, M. Jian, L. Gao, H. Wang, X. Zhang, Thin-film nanocomposite forward-osmosis membranes on hydrophilic microfiltration support with an intermediate layer of graphene oxide and multiwall carbon nanotube, ACS Appl. Mater. Interfaces 10 (2018) 34464-34474, https://doi.org/10.1021/acsami. 8 b10550.

[35] M.-B. Wu, Y. Lv, H.-C. Yang, L.-F. Liu, X. Zhang, Z.-K. Xu, Thin film composite membranes combining carbon nanotube intermediate layer and microfiltration support for high nanofiltration performances, J. Membr. Sci. 515 (2016) 238-244, https://doi.org/10.1016/j.memsci.2016.05.056.

[36] S. Al Aani, A. Haroutounian, C.J. Wright, N. Hilal, Thin film nanocomposite (TFN) membranes modified with polydopamine coated metals/carbon-nanostructures for desalination applications, Desalination 427 (2018) 60-74, https://doi.org/10. 1016/j.desal.2017.10.011.

[37] T. Ormanci-Acar, M. Mohammadifakhr, N.E. Benes, W.M. de Vos, Defect free hollow fiber reverse osmosis membranes by combining layer-by-layer and interfacial polymerization, J. Membr. Sci. (2020) 118277, https://doi.org/10.1016/j. memsci.2020.118277.

[38] K.Y. Wang, T. Matsuura, T.-S. Chung, W.F. Guo, The effects of flow angle and shear rate within the spinneret on the separation performance of poly(ethersulfone) (PES) ultrafiltration hollow fiber membranes, J. Membr. Sci. 240 (2004) 67-79, https:// doi.org/10.1016/j.memsci.2004.04.012.

[39] Y. Song, M. Wei, F. Xu, Y. Wang, Molecular simulations of water transport resistance in polyamide RO membranes: interfacial and interior contributions, Engineering (2020), https://doi.org/10.1016/j.eng.2020.03.008.

[40] N.Y. Yip, A. Tiraferri, W.A. Phillip, J.D. Schiffman, M. Elimelech, High performance thin-film composite forward osmosis membrane, Environ. Sci. Technol. 44 (2010) 3812-3818, https://doi.org/10.1021/es1002555.

[41] M. Mulder, Basic Principles of Membrane Technology, Kluwer Academic Publishers, 1996, p. p421.

[42] L. Paltrinieri, K. Remmen, B. Müller, L. Chu, J. Köser, T. Wintgens, M. Wessling, L.C.P.M. de Smet, E.J.R. Sudhölter, Improved phosphoric acid recovery from sewage sludge ash using layer-by-layer modified membranes, J. Membr. Sci. 587 (2019) 117162, https://doi.org/10.1016/j.memsci.2019.06.002.

[43] J. Sabín, C. Vázquez-Vázquez, G. Prieto, F. Bordi, F. Sarmiento, Double charge inversion in Polyethylenimine-decorated liposomes, Langmuir 28 (2012) 10534-10542, https://doi.org/10.1021/la3019259.

[44] C.V. Gherasim, T. Luelf, H. Roth, M. Wessling, Dual-charged hollow fiber membranes for low-pressure nanofiltration based on polyelectrolyte complexes: one-step fabrication with tailored functionalities, ACS Appl. Mater. Interfaces (2016), https://doi.org/10.1021/acsami.6b05706 acsami.6b05706.

[45] Z. Yang, H. Guo, C.Y. Tang, The upper bound of thin-film composite (TFC) polyamide membranes for desalination, J. Membr. Sci. 590 (2019) 117297, , https:// doi.org/10.1016/j.memsci.2019.117297.

[46] Y. Yang, Q. Zhang, S. Li, S. Zhang, Preparation and characterization of porous polyelectrolyte complex membranes for nanofiltration, RSC Adv. 5 (2015) 3567-3573, https://doi.org/10.1039/C4RA13699C.

[47] B.L. Welch, On the comparison of several mean values: an alternative approach, Biometrika 38 (1951) 330-336 (https://doi.org/https://www.jstor.org/stable/ 2332579).

[48] G.M. Geise, H.B. Park, A.C. Sagle, B.D. Freeman, J.E. McGrath, Water permeability and water/salt selectivity tradeoff in polymers for desalination, J. Membr. Sci. 369 (2011) 130-138, https://doi.org/10.1016/j.memsci.2010.11.054.

[49] N.Y. Yip, M. Elimelech, Performance limiting effects in power generation from salinity gradients by pressure retarded osmosis, Environ. Sci. Technol. 45 (2011) 10273-10282, https://doi.org/10.1021/es203197e. 